\title{
USEFUL TOOL TO ASSESS THE EFFICACY OF ACUTE PAIN SERVICE
}

\author{
Abigail Secker ${ }^{1}$, Serina Ruth Salins ${ }^{2}$
}

1 Medical Student, Bermingham, University, UK.

${ }^{2}$ Associate Professor, Department of Anaesthesia, Christian Medical College, Vellore, India.

\section{BACKGROUND}

ABSTRACT

Pain along with the tools to assess the types, severity and treatment have been extensively studied over the last few decades, and guidelines formulated. However, assessment of pain services have only recently gained importance, to prevent improper pain management. There is a current drive to improve the state of pain management in India. Considering the relative lack of available literature, this study is aimed to provide an insight into the quality of acute pain services (APS) at our health centre. Primarily looking at outcomes, measuring efficiency, safety and timeliness of the APS, by identifying areas requiring improvement.

\section{METHODS}

Standards for the study were selected from the Royal College of Anaesthetists (RCoA) recipe book for acute pain services. Data was collected over a six months period. The study included all patients under the care of the institutional Acute Pain Service (APS). Inference was made with regard to the standards achieved.

\section{RESULTS}

An average of 700 patients per month, with 3-10 days care under the acute pain services, were assessed. Our team met 6 of the 11 standards laid out; 3 standards were not met but deemed acceptable, and 2 standards were found to require improvement. 83\% ( $n=3901$ ) were deemed to have had adequate analgesia. 88\% of patient days were GOOD (only pain scores of 0-3), 9\% BORDERLINE (incidences of isolated high pain scores) and 3\% POOR (incidences of consequently high pain score) pain control.

\section{CONCLUSIONS}

This study identified a number of ways in which hospitals could improve their acute pain services. Continual development in following standardised guidelines, protocols, arrangement of ongoing training and education of pain team are of paramount importance, for the efficacy of the pain services. These were highlighted and upgraded. These simple measures can be recommended to be implemented for improvement of the acute pain management services in any hospital in India.

HOW TO CITE THIS ARTICLE: Secker A, Salins SR. Useful tool to assess the efficacy of acute pain service. J. Evolution Med. Dent. Sci. 2019;8(17):1412-1414, DOI: 10.14260/jemds/2019/314

\section{BACKGROUND}

Access to pain management is a fundamental human right. In India, literature shows that this is considered inadequate, secondary to excessively strict narcotics regulations, poor education and administrative issues. On the other hand, world over, there has been enormous advances in the field of pain, however, the knowledge and information not completely reaching the masses, particularly in the rural areas. The detrimental effects of undertreated pain, is well documented, posing both physical and socioeconomic burden. Primarily, implementations of Acute Pain Services have been to treat inadequate immediate postoperative pain. This prospective descriptive study was undertaken to prospectively review the quality of the Acute Pain Service (APS) at our high volume, tertiary level centre.

'Financial or Other Competing Interest': None.

Submission 09-03-2019, Peer Review 12-04-2019,

Acceptance 19-04-2019, Published 29-04-2019.

Corresponding Author:

Dr. Serina Ruth Salins,

Associate Professor

Department of Anaesthesia,

Christian Medical College,

Vellore,

India.

E-mail: serinaruthsalins@gmail.com

DOI: $10.14260 /$ jemds/2019/314

\section{(c) (i) $(9)$}

The main aim and objective was to evaluate the outcomes, measuring efficiency, safety, timeliness of APS, and to provide an overall perspective on the clinical scenario. However, there is a current drive to improve the state of pain management in India.(1)

\section{METHODS}

Following the ethics committee approval (IRB Min. No: 10049 [OBSERV] dated 20.04.2016), this prospective descriptive study, was conducted, over six month period. All patients, referred to the APS, were included. Each day counted as a new day for each patient, until discharge from the well-established decade old APS, at our tertiary level centre. Data was collected using a standard proforma based on standards and criteria set out in the Royal College of Anaesthetist (RCoA) audit recipe book.(2) This included patient demographics, medical history, comorbidities, duration of care and mode of treatment by the APS team, was analysed to what degree each standard had been met and whether appropriate analgesia was prescribed and administered.

No statistical method was used for data analysis.

\section{RESULTS}

Total of 4700 patients (600-900/month) were under APS care for $3-10$ days. $48 \%(n=2256)$ of patients had a completed record of pain scores, and 58\% $(n=2726)$ of patients with moderate-to-severe pain received analgesia within 15 minutes of assessment, $45 \%(n=1227)$ had a reduced pain score within 30 minutes and $2 \%(n=55)$ had no reduction in pain score, 
which eventually settled with aggressive therapy. 83\% $(n=3901)$ were deemed to have had adequate analgesia. In terms of total patient days under the care of the APS: $88 \%$ of patient days were GOOD (only pain scores of $0-3$ ), 9\% BORDERLINE (incidences of isolated high pain scores) and 3\% POOR (incidences of consequently high pain score) pain control. At our hospital, out of the 11 standards laid out in the RCoA recipe book, 6 standards were met, namely, established APS, pain is consistently recorded as a 5 th vital sign, uniform pain scoring system throughout the hospital, official training programme to educate staff, guidelines and protocols for pain management, none of the patients were referred to the APS before simple measures had been taken to control pain, 3 standards were not met but deemed acceptable, such as, completed pain records (48\%), high pain scores responded within 15 minutes (58\%), effective analgesia within 30 minutes after administration of analgesics (45\%), and 2 standards were found to require improvement, for example, consecutively high pain scores, without intervention(3\%), isolated high pain scores were recorded on $9 \%$ of patient days. Improvement in communication, documentation, urgency in treating moderate to severe pain within 15 minutes and ongoing upgrading of knowledge in pain management were emphasized, as they were considered as lacunae in the current system.

\begin{tabular}{|c|c|c|}
\hline Age & \multicolumn{2}{|c|}{ Sex } \\
\hline \multicolumn{3}{|l|}{ Presenting complaint } \\
\hline Reason for referral & \multicolumn{2}{|c|}{ Medical / Surgical/ Postoperative } \\
\hline \multicolumn{3}{|l|}{ Surgery / Diagnosis } \\
\hline \multicolumn{3}{|l|}{ Duration of pain managed by APS team } \\
\hline Vitals stable? & Yes & No \\
\hline Completed pain score record present? & Yes & No \\
\hline Is there more than one consecutively high pain score? & Yes & No \\
\hline Analgesia administered within 15 mins. of high pain score & Yes & No \\
\hline Reduced pain score within 30 mins. of treatment? & Yes & No \\
\hline Was the patient referred to APS before simple pain control measures has been taken? & Yes & No \\
\hline \multicolumn{3}{|l|}{ Last two recorded pain scores } \\
\hline \multicolumn{3}{|l|}{ Highest and lowest recorded pain scores } \\
\hline Analgesia method & \multicolumn{2}{|c|}{ Epidural /PCA / Oral medication } \\
\hline Epidural & Yes & No \\
\hline \multicolumn{3}{|l|}{ Level, drug, dose } \\
\hline \multicolumn{3}{|l|}{ Duration } \\
\hline PCA & Yes & No \\
\hline \multicolumn{3}{|l|}{ Drug dose } \\
\hline \multicolumn{3}{|l|}{ Lockout interval, duration } \\
\hline Adequacy of analgesia & Yes & No \\
\hline \multicolumn{3}{|l|}{ If inadequate what was done } \\
\hline Complications & Yes & No \\
\hline $\begin{array}{l}\text { Nausea, vomiting, pruritus, constipation, } \\
\text { unilateral block, infection, catheter issues, }\end{array}$ & \multicolumn{2}{|c|}{$\begin{array}{c}\text { urinary, retention, equipment failure } \\
\text { overdose }\end{array}$} \\
\hline \multicolumn{3}{|l|}{ What was done for complications } \\
\hline \multicolumn{3}{|l|}{ Table 1. Proforma } \\
\hline
\end{tabular}

\begin{tabular}{|c|c|c|c|}
\hline Sl. No. & Criteria & Target & Health Centre \\
\hline 1. & There should be an established acute pain service & Yes & Yes \\
\hline 2. & Pain should be recorded as a 5 th vital sign & Yes & Yes \\
\hline 3. & $\begin{array}{c}\text { There should be a uniform pain scoring system used } \\
\text { throughout the hospital }\end{array}$ & Yes & Yes \\
\hline 4. & There should be ongoing education about pain management & Yes & Yes \\
\hline 5. & $\begin{array}{c}\text { Standardised current guidelines and protocols available for } \\
\text { the management of pain }\end{array}$ & Yes & Yes \\
\hline 6. & $\begin{array}{l}\text { Patients with painful conditions should have a complete } \\
\text { record of pain scores }\end{array}$ & $100 \%$ & $48 \%$ \\
\hline 7. & $\begin{array}{c}\begin{array}{c}\text { Patients should not be experiencing consecutively high pain } \\
\text { scores }\end{array} \\
\end{array}$ & $\begin{array}{l}0 \% \text { patient days } \\
(<5 \% \text { acceptable })\end{array}$ & $03 \%$ \\
\hline 8. & $\begin{array}{l}\text { Patients should not be experiencing isolated high pain } \\
\text { scores }\end{array}$ & $\begin{array}{l}<5 \% \text { patient days } \\
(<10 \% \text { acceptable })\end{array}$ & $09 \%$ \\
\hline 9. & $\begin{array}{l}\text { High pain scores should be responded to within } 15 \text { minutes } \\
(100 \%)\end{array}$ & $100 \%$ & $58 \%$ \\
\hline 10. & Pain scores should reduce within 30 minutes of treatment & $95 \%$ & $45 \%$ \\
\hline 11. & $\begin{array}{c}\text { Patients should not be referred to the APS before simple } \\
\text { measures have been made to control pain }\end{array}$ & $0 \%$ & $0 \%$ \\
\hline
\end{tabular}




\section{DISCUSSION}

Pain, as defined by the International Association for the Study of Pain (IASP) is "an unpleasant sensory and emotional experience associated with actual or potential tissue damage, or described in terms of such damage."(1) The World Health Organization describes over $80 \%$ of the world's population as living without adequate access to treatment for pain.In India, there is a serious dearth of data on pain.(3)

Since its inception in 1985, the Acute Pain Service, has been rapidly evolving and widely accepted as the standard of care for postoperative analgesia.(4) Over the last decade, this need is recognised, even in the developing countries, however, there is room for improvement, in terms of education and training. (5, 6, 7) Implementation of "fast track" surgical pathways, is the way forward in the management of acute pain after surgery. This can be achieved by opioid-sparing, multimodal, procedure-specific analgesia, acute rehabilitation after surgery. Advantages of these cannot be over-emphasised. In addition to use of local and regional anaesthesia, both central and peripheral blocks, systemic analgesia include, paracetamol (Acetaminophen), non-selective and COX-2 selective NSAIDs, Alpha-2-delta modulators (Gabapentin, pregabalin), NMDA-receptor antagonists (Ketamine), Alpha-2 adrenergic agonists (Clonidine, dexmedetomidine), systemic local anaesthetics, corticosteroids. Evidence-based guidelines by way of Procedure-Specific Postoperative Pain Management (PROSPECT) are recommended to be implemented, as analgesic requirement varies with the type of surgery.(8) Additionally, protocols for enhanced recovery after surgery, is also well established, for better post-operative outcomes. Information technology has emerged as one of the important non-pharmacologic and alternative therapies, complementing the traditional management of acute pain.(9) Using the Royal College of Anaesthesia(RoCA), acute pain management recipe protocol,(10) as the background, to assess our patients for acute postoperative pain, we found $83 \%$ adequate analgesia, which is a fairly satisfactory, however, needs to be improved to a $100 \%$. Scandinavian University Hospital, studied the effectiveness and challenges encountered by the APS team, which showed, reduction in pain intensity acutely, lesser incidence of chronic pain state, even in patients with several comorbidities, such as, psychiatric diseases, opioid dependency and chronic pain.(11)

Globally, the greatest obstacles to effective pain management, are lack of training healthcare workers, inadequate resources, opioid restrictions, malalignment of government policies (IASP-2018). The solutions, being effective training programmes, medication access and availability, regulation of controlled medications, adequate supply and appropriate distribution.(12)

This study identified ways in which the APS could improve, such as, development of standardized guidelines, protocols, training programme to educate all staff, pain nurses of proper documentation, swift response to high pain scores with appropriate analgesics.

\section{CONCLUSIONS}

This study demonstrates that it is possible to run an APS service within the infrastructure that is available in most Indian hospitals. Beside the benefits of APS in reducing pain intensity, the clinical challenges highlight the areas of potential problems and barriers.

\section{REFERENCES}

[1] Jain PN, Bakshi SG, Thota RS. Acute pain services in India: a glimpse of the current scenario. Journal of Anaesthesiology Clinical Pharmacology 2015;31(4):554-7. https://doi.org/10.4103/09709185.169088.

[2] 'Audit Recipe Book. 3rd edition. 2012. The Royal College of Anaesthetists'. Accessed 5th January 2018. https://www.rcoa.ac.uk/document-store/auditrecipe-book-3rd-edition-2012.

[3] Sharma, Kanika. Pain is the silent epidemic that India's health systems are failing to handle. Text. Scroll.in. Accessed March 17, 2019 https://scroll.in/pulse/829320/pain-is-the-silentepidemic-that-indias-health-systems-are-failing-tohandle.

[4] Tawfic QA, Faris AS. Acute pain service: past, present and future. Pain Manag 2015;5(1):47-58.

[5] Charlton E. Core curriculum for professional education. $3^{\text {rd }}$ edn. Seattle: IASP Press 2005.

[6] Soyannwo OA, Obstacles to pain management in lowresource settings. In: Kopf A, Patel NB, eds. Guide to pain management in low-resource settings. Seattle: IASP 2010: p. 9-11.

[7] Bond M. A decade of improvement in pain education and clinical practice in developing countries: IASP initiatives. British Journal of Pain 2012;6(2):81-4.

[8] Procedure-Specific Postoperative Pain Management (PROSPECT). https://www.postoppain.org/

[9] Tedore T, Weinberg R, Witkin L, et al. Acute pain management/regional anesthesia. Anesthesiol Clin 2015;33(4):739-51.

[10] Vickers A, Grady K. Pain medicine. Section 11. Raising the standard: a compendium of audit recipes. $3^{\text {rd }}$ edn. Royal College of Anaesthetists 2012.

[11] Miclescu A, Butler S, Karlsten R. The changing face of acute pain services. Scandinavian Journal of Pain 2017;16(1):204-10.

[12] www.iasp-pain.org/globalyear for Excellence in Pain Education, 2018. 